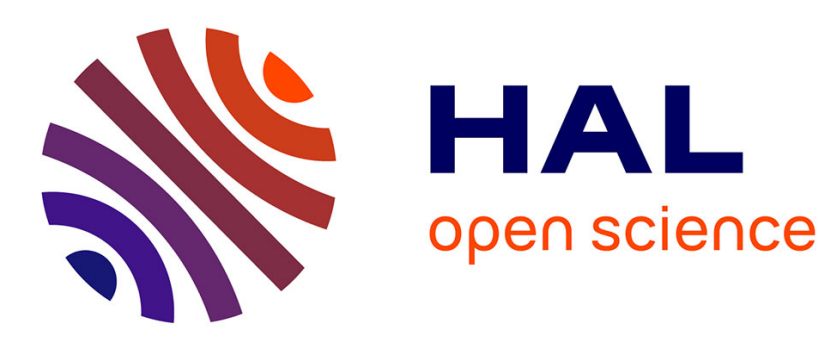

\title{
Hydrogenation of GaAs covered by GaAlAs and subgrain boundary passivation
}

\author{
A. Djemel, J. Castaing, Jacques Chevallier, P. Henoc
}

\section{To cite this version:}

A. Djemel, J. Castaing, Jacques Chevallier, P. Henoc. Hydrogenation of GaAs covered by GaAlAs and subgrain boundary passivation. Journal de Physique III, 1992, 2 (12), pp.2301-2307. 10.1051/jp3:1992247 . jpa-00248883

\section{HAL Id: jpa-00248883 https://hal.science/jpa-00248883}

Submitted on 1 Jan 1992

HAL is a multi-disciplinary open access archive for the deposit and dissemination of scientific research documents, whether they are published or not. The documents may come from teaching and research institutions in France or abroad, or from public or private research centers.
L'archive ouverte pluridisciplinaire HAL, est destinée au dépôt et à la diffusion de documents scientifiques de niveau recherche, publiés ou non, émanant des établissements d'enseignement et de recherche français ou étrangers, des laboratoires publics ou privés. 
Classification

Physics Abstracts

$78.60-62.20 \mathrm{~F}-61.70 \mathrm{~N}$

\title{
Hydrogenation of GaAs covered by GaAlAs and subgrain boundary passivation
}

\author{
A. Djemel $\left({ }^{1},{ }^{*}\right)$, J. Castaing $\left({ }^{1}\right)$, J. Chevallier $\left({ }^{2}\right)$ and P. Henoc $\left({ }^{3}\right)$ \\ (1) Laboratoire de Physique des Matériaux, C.N.R.S. Bellevue, 92195 Meudon Cedex, France \\ (2) Laboratoire de Physique des Solides de Bellevue, France \\ (3) PMM/MPD, C.N.E.T., 196 avenue Henri Ravera, 92220 Bagneux, France
}

(Received 21 April 1992, accepted 12 August 1992)

\begin{abstract}
Résumé. - La cathodoluminescence (CL) a été utilisée pour étudier l'influence de l'hydrogène sur les propriétés électroniques de GaAs nu et recouvert d'une couche de GaAlAs. Le caractère recombinant des sous-joints de grains a été examiné. Ces défauts étendus ont été introduits par déformation plastique à chaud. Les résultats montrent que l'hydrogène passive ces défauts. La pénétration de l'hydrogène à l'intérieur de GaAs est retardée par la présence de la couche de GaAlAs.

Abstract. - Cathodoluminescence (CL) has been performed to study the influence of hydrogen on electronic properties of GaAs with and without a GaAlAs layer. Recombination at sub-boundaries has been examined. These extended defects have been introduced by high temperature plastic deformation. The results show that they are passivated by hydrogen. The penetration of hydrogen is slowed down by the GaAlAs layer.
\end{abstract}

\section{Introduction.}

Hydrogen has been shown to induce important modifications of the electronic and optical properties of semiconductors in their single crystalline, polycrystalline and amorphous states. In silicon, the three kinds of materials have been examined in relation with the presence of hydrogen. In GaAs, the investigations have been mostly centered on point defects in single crystals ; they have shown that impurities associated with shallow as well as deep levels can be passivated by hydrogen. These properties have been reviewed in various papers $[1,2]$.

In a recent work [3], we have shown that the presence of hydrogen considerably enhances the cathodoluminescence and that it does not seem to influence recombination properties of subgrain boundaries in deformed GaAs. In this work [3], the role of surface recombination was not determined.

(*) Permanent address : Laboratoire Physique du Solide, Université de Constantine, Algérie. 
In the present work, we have deposited a layer of GaAlAs on top of deformed GaAs, in order to decrease the carrier recombination at the surface. This modified the hydrogen penetration in the materials. We conclude that subgrain boundaries are passivated by hydrogen.

\section{Experimental techniques.}

The conditions are identical to those of our previous work [3]. Semi insulating LEC GaAs has been used. High temperature plastic deformation was performed in order to introduce the subgrain boundaries [4-7]. After deformation, the specimens became p-type $\left(p \sim 10^{16} \mathrm{~cm}^{-3}\right)$ [8]. In order to have a reference for the purpose of comparison of electronic properties, we have used bulk and epitaxial GaAs (layer thickness : $2 \mu \mathrm{m}$ ) doped with $\mathrm{Zn}$, having hole concentrations of $8 \times 10^{18} \mathrm{~cm}^{-3}$ and $10^{18} \mathrm{~cm}^{-3}$ respectively.

For the three kinds of specimens, the surface recombination velocity of GaAs was modified by depositing a layer of GaAlAs (aluminium concentration : $27 \%$ ). The layer was made by OMCVD at a temperature of $750^{\circ} \mathrm{C}$ during one minute, giving a thickness of $50 \mathrm{~nm}$. The role of the GaAlAs overlayer on the recombination velocity may be explained along two lines. Because of a residual silicon doping (about $10^{16} \mathrm{~cm}^{-3}$ ) during the OMCVD deposition, a n/p junction is formed on top of the specimens, giving rise to an inward electrical field $E$. The injected electrical carriers are separated by $E$, with electrons accumulated at the surface, thus preventing recombination. The second mechanism is related to the larger bandgap of GaAlAs $(1.8 \mathrm{eV})$ compared to $\mathrm{GaAs}(1.4 \mathrm{eV})$. If the above mentioned junction effect is absent, the carriers still meet a potential at the interface, preventing them to reach the surface.

To introduce hydrogen, the specimens were exposed to a RF plasma during $90 \mathrm{mn}$, at a temperature of $240{ }^{\circ} \mathrm{C}$. A power density of $0.04 \mathrm{~W} / \mathrm{cm}^{2}$ and a pressure of $100 \mathrm{~Pa}$ are typical values of the hydrogenation parameters. The same process was used for the three kinds of specimens.

Deuterium has been used instead of hydrogen in order to be able to perform secondary ion mass analysis (SIMS) in a CAMECA IMS 4F apparatus. The profiles were obtained in similar conditions. Cesium ion primary beams between 105 and $120 \mathrm{nA}$ were used giving crater depths from 7 to $8.5 \mu \mathrm{m}$ after $50 \mathrm{mn}$ erosion times. The background intensity for GaAs without deuterium was between 0.1 and $1 \mathrm{count} / \mathrm{s}$; we retained data when they were significantly larger than these values.

Cathodoluminescence (CL) was performed, at room temperature, in a scanning electron miscroscope (SEM), collecting the light in the $300-900 \mathrm{~nm}$ wavelength range.

\section{Results and discussion.}

3.1 HYDROGEN DIFFUSION PROFILES. - The two different kinds of specimens, i.e. with and without GaAlAs layers, display different hydrogen profiles (Fig. 1).

For GaAs without GaAlAs, the hydrogen concentration-penetration curves are typical of diffusion in p-type semiconductors [2]. First, a plateau is observed (Fig. 1) at a concentration level close to that of active acceptors ; indeed, the largest amount of $\mathrm{Zn}$ corresponds to the highest hydrogen solubility (Figs. $1 \mathrm{~b}$ and $1 \mathrm{c}$ ). The extension of the plateau and the drop which follows depend on the parameters of the hydrogenation [2]. The experiments of figures $1 \mathrm{~b}$ and 1c have been performed in the same conditions which explain the good reproducibility of the results. The mechanism of hydrogen diffusion is ascribed to the motion of neutral $\mathrm{H}$ and of $\mathrm{H}^{+}$, with a larger contribution of $\mathrm{H}^{+}$which forms acceptor-proton complexes [2].

The curve for deformed GaAs without GaAlAs shows the same features (Fig. 1a) as expected for p-type materials [2] ; however, we cannot proceed in the analysis of the results along the same line as for $\mathrm{Zn}$-doped GaAs, since we do not know the exact nature of acceptor levels in deformed GaAs [8]. 


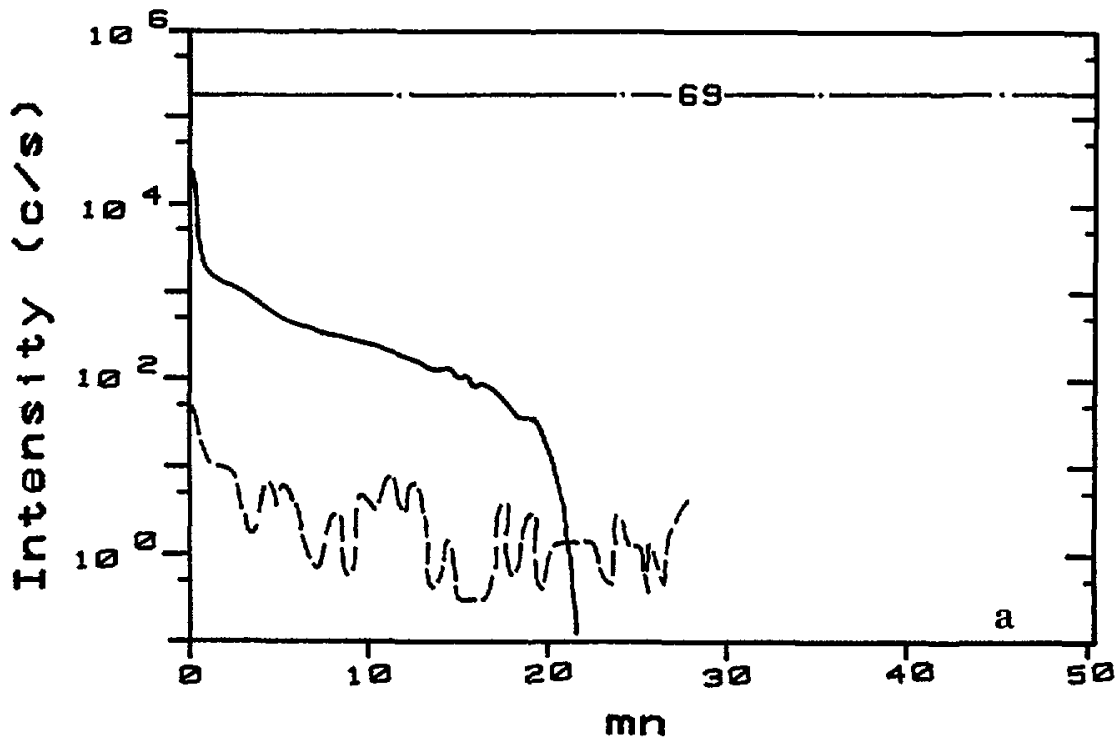

a)

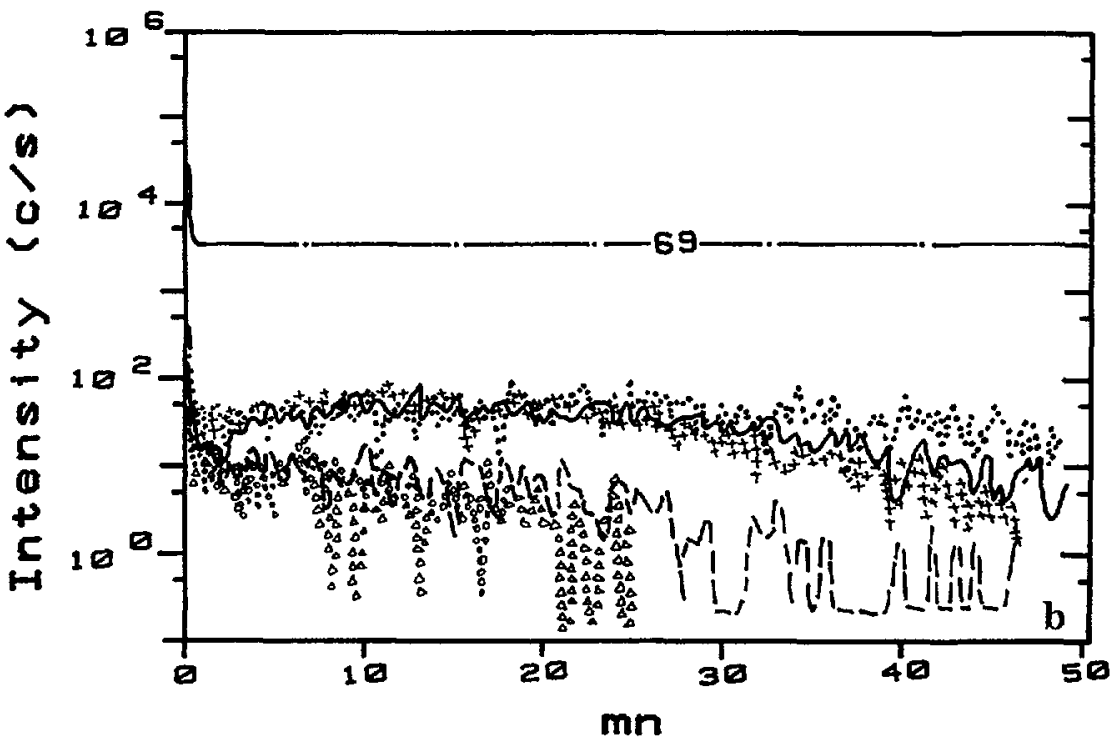

b)

Fig. 1. - Hydrogen penetration profiles in p-type GaAs measured as deuterium concentrations versus erosion times. The curves are normalized by reference to the intensity of ${ }^{69} \mathrm{Ga}$. a) deformed specimens, b) epitaxial GaAs, c) bulk crystal. In the three cases, the high deuterium concentration corresponds to $\mathrm{GaAs}$ without GaAlAs layer. Similar conditions have been used for SIMS analysis along 7 to $8.5 \mu \mathrm{m}$ depths. 


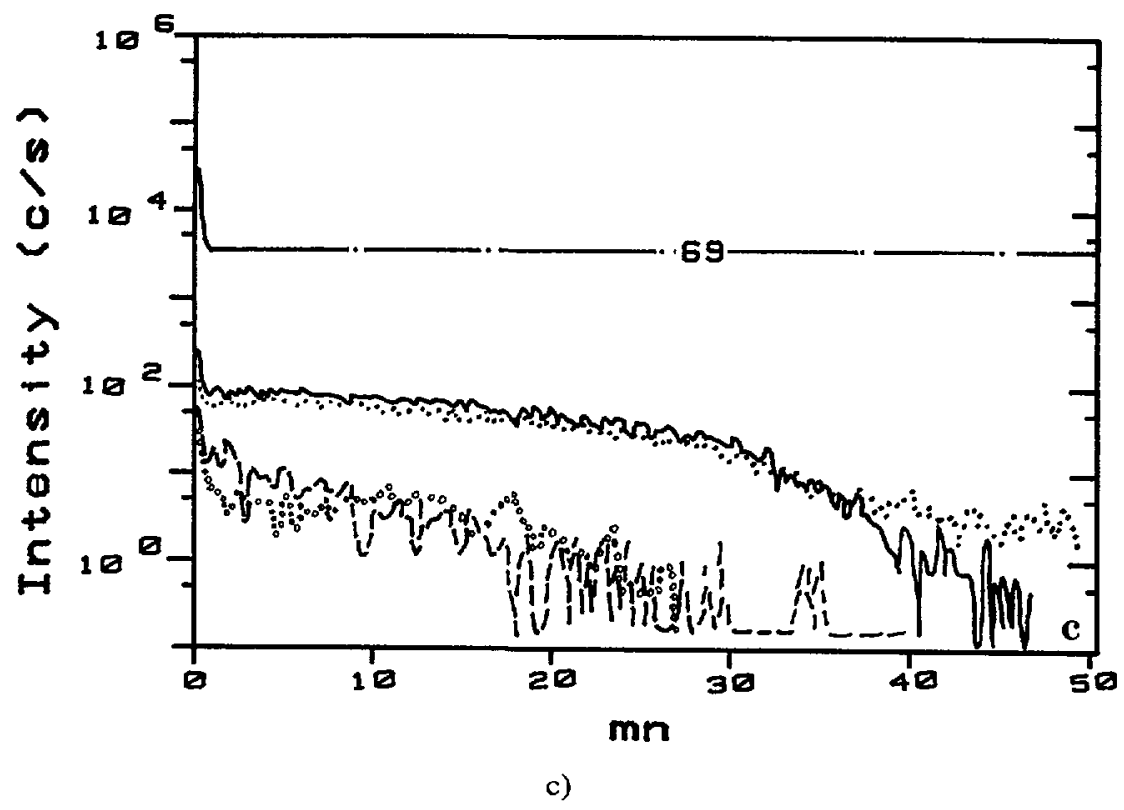

Fig. 1 (continued).

In all kinds of specimens, the presence of a GaAlAs layer decreases the hydrogen diffusivity, giving lower hydrogen concentration for similar experimental conditions (Fig. 1). A very thin layer of GaAlAs $(50 \mathrm{~nm})$ is a barrier for hydrogen diffusion in p-type GaAs, with a detectable hydrogen distribution extending only on 2-3 $\mu \mathrm{m}$ from the surface (Figs. $1 \mathrm{~b}$ and $1 \mathrm{c}$ ). Such effects have been observed by Antell et al. [9] and Pearton et al. [10] in similar structures.

The introduction of hydrogen in n-type $\mathrm{Ga}_{1-x} \mathrm{Al}_{x} \mathrm{As}$ has been studied by Chevallier et al . [11] in thick, lightly and highly silicon doped epitaxial layers with $0<x<0.3$. Deuterium plasma exposure conditions were close to that used in the present work. It was shown that solubilities of hydrogen in GaAs and GaAlAs were close to each other and that the hydrogen diffusion mechanisms were somewhat different. However, no barrier effect for hydrogen diffusion was found in GaAlAs. From the analysis of the hydrogen profiles for different $x$ and doping levels, it was inferred that $\mathrm{H}^{-}$is the dominant diffusing species in lightly silicon doped $\mathrm{n}-\mathrm{Ga}_{1-x} \mathrm{Al}_{x} \mathrm{As}$ with $x \cong 0.29$ [11].

The presence of a $\mathrm{n} / \mathrm{p}$ junction at the GaAlAs/GaAs interface and the difference in the band gaps of the semiconductors create an inward electrical field $E$. The effect of this electrical field $E$ is to prevent the penetration of the $\mathrm{H}^{-}$ions in the GaAlAs layer which becomes a diffusion barrier. This explains the hydrogen profiles in GaAs (Fig. 1).

3.2 Cathodoluminescence (CL) OBSERVATIONS AND Boundary Passivation. - The presence of the GaAlAs layer increases the CL signal by a factor 1.7 compared to bare GaAs, for experiments performed with $20 \mathrm{keV}$ electrons. This can be ascribed to the expected decrease in surface recombination velocity due to GaAlAs. A similar effect has been observed in photoluminescence experiments by Dautremont-Smith et al. [12].

The CL signal is also increased by the presence of hydrogen in GaAs [3]. We have made the same observation for the specimens with GaAlAs. 


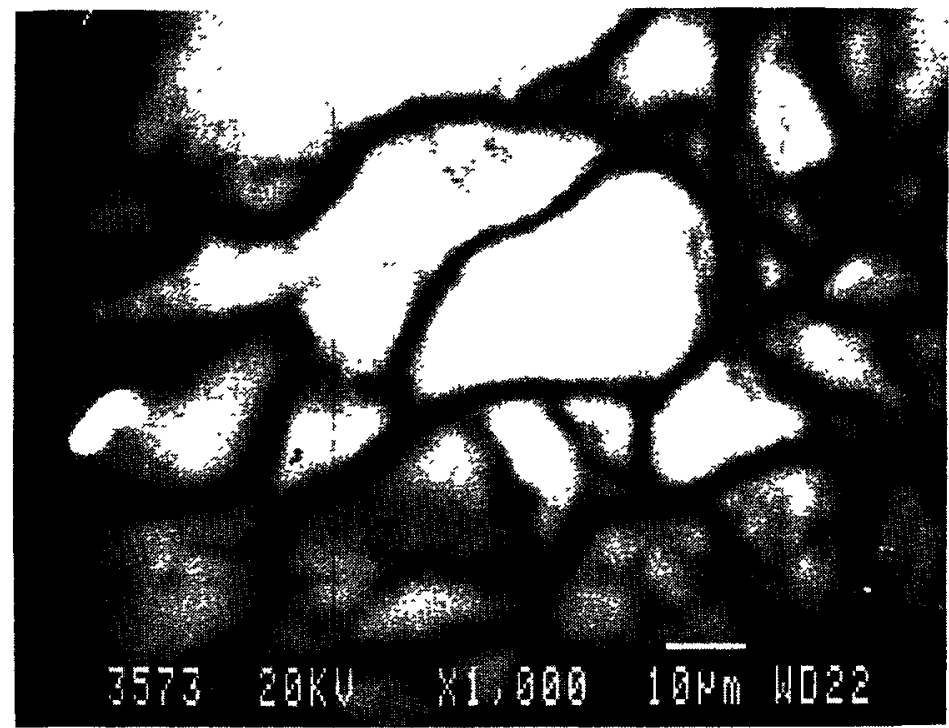

Fig. 2. - CL micrograph of GaAs after deformation at $1004{ }^{\circ} \mathrm{C}$, and then covered by a thin GaAlAs layer. Beam accelerating voltage $20 \mathrm{keV}$.

The subgrain boundaries introduced in GaAs single crystals by plastic deformation are easily observed by CL [3]. This is not modified when they are covered with GaAlAs (Fig. 2). After the introduction of hydrogen, the contrast of the boundaries is largely decreased (Fig. 3b).

We have further checked that the $C L$ emission originates from the subsurface region containing hydrogen, by changing, for the specimens with GaAlAs, the penetration range of electrons. The values are $1.6 \mu \mathrm{m}, 2.6 \mu \mathrm{m}$ and $3.7 \mu \mathrm{m}$ respectively, for $15 \mathrm{keV}, 20 \mathrm{keV}$ and $25 \mathrm{keV}$ beam voltages. CL images obtained in the three conditions are shown in figure 3 . The boundaries are almost invisible at low beam voltage (Fig. 3a) when electron hole pairs are created in the hydrogenated part of the materials, i.e. ; 1-2 $\mu \mathrm{m}$ from the surface (10 mn in Fig. 1a). For high voltages, the boundary contrast is strong (Fig. 3c) because the penetration of hydrogen is small compared to that of electrons.

An alternative explanation is that the decrease of boundary contrast close to the surface is due to the fact that the CL signal is formed in the depleted zone of the $\mathrm{n} / \mathrm{p}$ junction, where the electric field $E$ is strong. By analogy with electron beam induced current (EBIC) studies [13], we infer that the CL contrast is decreased by $E$ because the minority carriers are attracted to the surface where they recombine rather than at the boundaries. This is not observed in our experiments since the boundary contrast is as strong with the presence of GaAlAs (Fig. 2) as without it [3] ; we can discard the influence of $E$ on the CL contrast.

The observation of strong boundary contrast when hydrogenated $\mathrm{GaAs}$ is not covered with a GaAlAs layer [3], can be ascribed to a surface effect; the recombination velocity remained large at the emergence of defects at the GaAs surface. This could be explained by the presence of damage in hydrogenated GaAs (Ga droplets) [2], nucleating on these emergences more easily than in GaAlAs. This could have been helped by the hydrogenation conditions (RF plasma power density) of reference [3] which were likely to induce such damage compared to those of the present work.

In conclusions, surface properties render $\mathrm{CL}$ observations difficult in GaAs. The subgrain boundaries are passivated by hydrogen, a behaviour analogous to that of silicon [14]. 

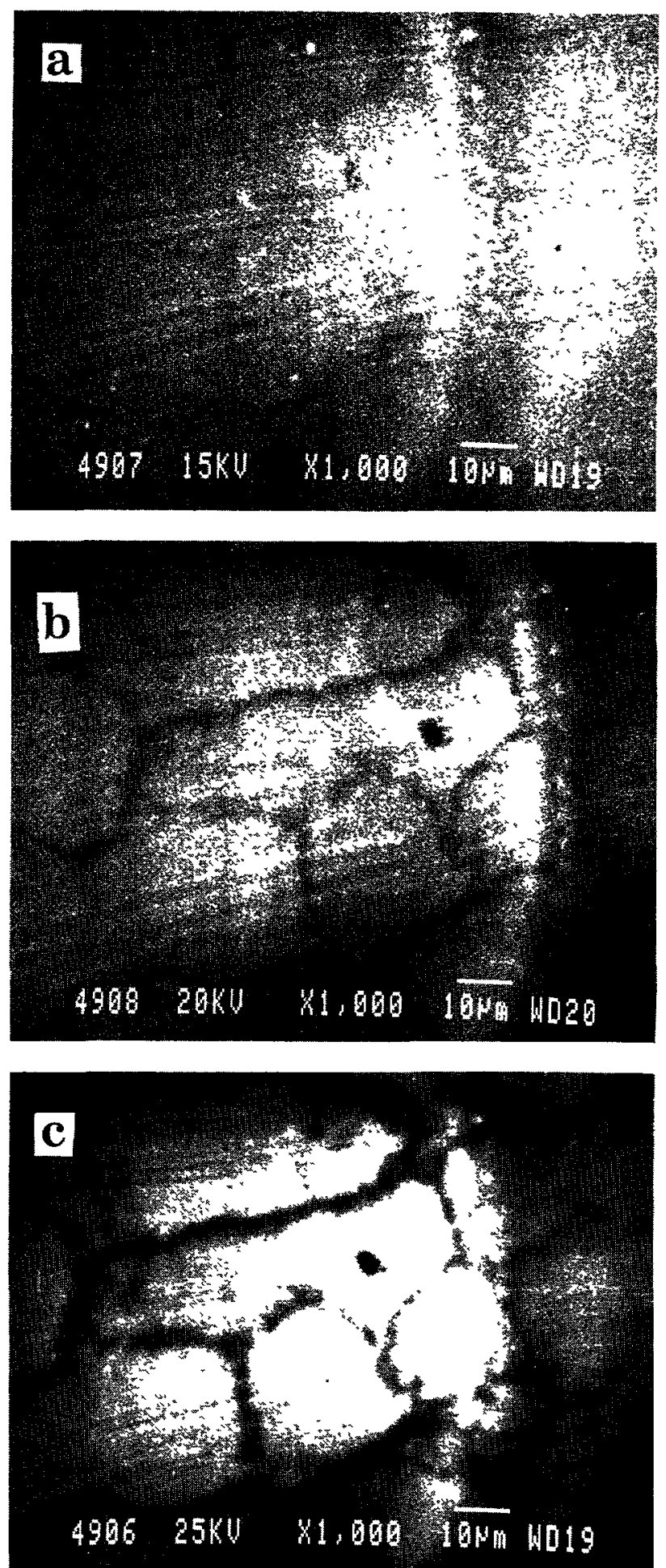

Fig. 3. - CL micrographs of deformed GaAs covered with a layer of GaAlAs and exposed to a hydrogen plasma. Observations for various beam accelerating voltages: a) $15 \mathrm{keV}$, b) $20 \mathrm{keV}$, c) $25 \mathrm{keV}$. 


\section{Acknowledgements.}

The authors thank C. Dolin for performing the SIMS experiments. They are grateful for the support of DRS (Algeria) and CNRS (France), in particular in the frame of a collaborative exchange program.

\section{References}

[1] Chevallier J., Aucouturier M., Ann. Rev. Mater. Sci. 18 (1988) 219.

[2] Chevallier J., Clerjaud B., Pajot B., Semicond. Semimet. 34, Chap. 13 (Academic Press, 1991) pp. 447-510.

[3] Djemel A., Castaing J., Chevallier J., Rev. Phys. Appl. 23 (1989) 1337.

[4] Djemel A., Castaing J., Europhys. Lett. 2 (1986) 611.

[5] DJemel A., Castaing J., Duseaux M., Philos. Mag. A 57 (1988) 671.

[6] Djemel A., Castaing J., Burle-Durbec N., Pichaud B., Rev. Phys. Appl. 24 (1989) 779.

[7] Jimenez-Melendo M., DJemel A., Rivière J. P., Castaing J., Thomas C., Duseaux M., Rev. Phys. Appl. 22 (1988) 251.

[8] DJEMEL A., Thèse d'état, Université d'Orsay (1988).

[9] Antell G. R., Briggs A. T. R., Butler B. R., Kitching S. A., Stagg J. P., Chew A., Sykes D. E., Appl. Phys. Lett. 53 (1988) 758.

[10] Pearton D. J., Dautremont-Smith W. C., Lopata J., Tu C. W., Abernathy C. R., Phys. Rev. $B 36$ (1987) 4260.

[11] Chevallier J., Machayekhi B., Grattepain C. M., Rahbi R., Theys B., Phys. Rev. 45 (1992) 8803.

[12] Dautremont-Smith W. C., Nabity J. C., Swaminathan V., Stavola M., Chevallier J., Tu C. W., Pearton S. J., Appl. Phys. Lett. 49 (1986) 1098.

[13] Farvacque J. L., Sieber B., Rev. Phys. Appl. Colloq. 6 (1989) C6-165.

[14] Aucouturier M., Physica B 170 (1991) 469. 